\title{
GYNAECOMASTIA IN STILBOESTROL WORKERS
}

\author{
BY \\ M. PATRICIA FITZSIMONS \\ From the Glaxo Laboratories, Greenford
}

Twenty cases of gynaecomastia among 38 men engaged in the manufacture of stilboestrol are described and the manner in which control of this industrial hazard was achieved. The account is based solely on clinical examination of the breasts, except in three cases where histological reports were obtained.

In February 1940, some of the men working on the stilboestrol plant noticed that their breasts were becoming enlarged. Therefore all those who had been exposed to stilboestrol at any stage of research or manufacture were examined, and in most, swellings in the mammary area were found. Later, work with dienoestrol also caused symptoms in one research chemist. This established that there was an occupational risk in the manufacture of all oestrogens.

While it was known that the administration of large amounts of oestrogens caused overgrowth of the fibrous supporting tissue of the breast, it had not been realized that small amounts of stilboestrol, absorbed during manufacture under apparently good conditions, could cause such marked physical signs. Dunn (1940) reported gynaecomastia and diminution of sexual function after a course of $5 \mathrm{mg}$. stilboestrol daily by the mouth for about two months, and since then references have been made in the medical journals to enlargement of the breast during the course of stilboestrol therapy for prostatic cancer.

The first twelve cases, two of which were described by Scarff and Smith (1942), occurred in 1940, the others appeared one by one in the following three years ; the last three, two in March 1942 and one in July 1943, were caused by accidental defects in the methods of protection adopted. The fact that one was submitted to operation shows the necessity for considering occupational gynaecomastia in the differential diagnosis of breast swellings in the male.

\section{Clinical Findings}

The first group of men examined included chemical process workers, research chemists, analytical chemists and pharmacists; the periods of exposure varied from two weeks to eighteen months. The first symptom was tingling in the nipple, often hardly noticeable unless chafing by braces occurred, when the tingling became soreness. This sometimes developed within four days of exposure, but more usually took about three weeks. Some complained of tingling in the nose and flushing, and one of frequency of micturition and temporary impotence. At the start there were often no physical signs. Later, a small area of thickening could be felt, usually under the areola, often unilateral ; this might subside within a few weeks if absorption had been minimal, or the thickening might enlarge into a nodule which sometimes enlarged further into a hemispherical swelling with all the appearance of the female adolescent breast, or expanded into one quadrant forming a well marked mass. Later still, a sub-areolar plaque about the thickness of a florin might be felt which gradually became smaller, often resolving into a small area of induration around the nipple before finally disappearing. Occasionally a swelling developed away from the region of the nipple, along the edge of the pectoral muscle, apparently in the axillary tail of the breast.

In addition to the asymmetry so commonly present there appeared to be a difference in reaction in each breast, shown by different rates of growth and regression. Case 2 (v.i.) showed this feature well; the right breast had all the appearances of a wellestablished lesion for at least three weeks before there was any appreciable abnormality in the left. In Case 13 a hard mass formed in ten days, and in Case 1 well marked swelling and feminization developed during one month of exposure. On the other hand, tumour formation was delayed for some months after removal from exposure in Cases 9 and 18 . The plaque stage subsided in about two months in Case 13, whereas in Case 19 it lasted for nine months. This stage was reached after eighteen months in Case 1, but histologically there was evidence of marked stimulation of mammary activity. This man left, and he and two others who also left shortly after being affected are the only men in whom there are no residual abnormal physical signs.

The plaque stage would appear to represent the final contraction of the fibrous tissue but, if this is so, it throws a doubt on whether early physical signs are readily detectable. In Case 18 examinations at short intervals were made and the first sign detected was a plaque some four months after exposure ; in Case 2 it seems unlikely that the left breast was unaffected until five weeks after the right, and that a new lesion appeared there while that in the right was subsiding; it is more reasonable to suggest that the proliferation of fibrous tissue in the left mammary area was at first undetected.

\section{Routes of Absorption}

It soon became obvious that the drug could be absorbed from numerous sources during the final stages of manufacture and in handling the finished product. Certain solutions could permeate the 
skin rapidly and resinous solutions were difficult to remove from the skin. When spills or splashes occurred on overalls, gloves, benches or apparatus, evaporation of the solvent left a powder which could be absorbed through the respiratory tract or through the skin, particularly if there was friction from cuff or collar. The powder is electrostatic and too light to be controlled by any draught control or exhaust apparatus. Atmospheric contamination was therefore common and difficult to eliminate.

\section{Preventive Measures}

Ordinary precautionary measures thought suitable for the handling of any powerful drug in light powder form had been taken before the trouble was reported. When the risk was found to be so great more stringent precautions were enforced. Closed apparatus was used where possible; protective overalls, gloves, and masks were supplied, and cleanliness of benches, apparatus and workrooms was enforced. Contaminated cleaning materials were destroyed. However, fresh cases of gynaecomastia continued to appear in men who were apparently intelligent, clean and careful workers. Women were not permitted to do the work, because detection of signs of absorption would be difficult. Finally, at the end of 1940, a new stilboestrol department was designed. Work started and by April 1941 , a carefully planned routine was prepared and an attempt was made to assess the degree of atmospheric contamination by animal tests.

The department consisted of: (1) an undressing room, where all clothing was put into lockers, and clean vests, flannel trousers, tennis shoes, overalls and caps were assumed; this led through (2) a showerbath (not used on the way in) into (3) the main workroom. This contained (4) a small drying room, later fitted with an air-lock door and an outlet for carrying away hot air. Only in this small room was the powder handled, the operator before entering donning an extra overall, gloves and respirator, kept in the large clean room. The gloves and respirator were cleaned when he returned from the small room and the cleaning rags deposited in a bin. At the end of a shift all clothing was deposited in a sack, the operator walked into the shower and thence back to the dressing room where he dried and dressed himself. The sack of contaminated clothing was removed and washed by a woman trained for the purpose. The floor was tiled and it was hosed at the end of each shift. Unfortunately there were many overhead pipes which caused difficulty during the periodic cleanings that were found to be necessary. Apparatus was washed immediately after use. All spills were wiped up and the rags deposited in the bin.

The staff consisted of selected volunteers, chemists or pharmacists, familiar with the care necessary in handling powerful drugs, and two cleaners. Work in the department was restricted to two weeks at a time, followed by at least one week on other work. The shift lasted from 7.30 a.m. to 1.30 p.m., and during this time no one left the department for any purpose, nor did anyone enter it. Men with physical signs were not allowed to continue this work; but there was one man who worked without symptoms from November 1940, to the summer of 1943.

\section{Animal Tests}

After preliminary experiments groups of ovariectomized mice were placed for periods of three days in various parts of the main room, usually outside the drying cabinet door and near the cleaner's sink-the former position being that where contamination from dust was most likely to occur, the latter the point furthest from this source of contamination and also where contamination from an unskilled worker might be expected. The vaginal smear technique was used and in May and early July 1941, all tests were positive. After the main room was cleaned they remained negative until early October. During October and November they fluctuated, sometimes one group being positive, sometimes the other, sometimes both. During this period efforts were made to discover the cause of the positive tests and various counter-measures were tried. A wet blanket was hung outside the drying cabinet door; later the air-lock door was added. The two cleaners were watched to see if one was dislodging more dust than the other. An attempt was made to space the cleaning of the department according to the tests, but this was not successful. In January 1942, the tests were again positive; this was possibly due to two factors, increased production and absence through sickness of one cleaner. Owing to the scarcity of mice, the tests were omitted until May 1942, but from then on until June 1943, all were negative. They were then discontinued. Occasionally it was suggested that the tests were inconclusive. An amount of stilboestrol that caused oestrus in mice need not cause symptoms in the men. Nevertheless we found that the tests were negative when performed early in the week after the department had been shut for the week-end and that after the mouse test had been positive a thorough cleaning was followed by a negative one. The aim was to achieve an atmosphere free from stilboestrol; without the animal tests conditions might have been thought to be perfect. Cumulative absorption of minute amounts-found on one occasion to be $0.2 \mathrm{mg} . / 300 \mathrm{cu}$. feet air, and on another to be unweighable-might have affected the men in whom clinical examination did not reveal any abnormality.

\section{Summary}

Twenty cases of gynaecomastia occurring among 38 men engaged in the manufacture of stilboestrol are described. An account is given of the preventive measures found necessary to protect the work-people.

I wish to express my appreciation of the cooperation given in the investigation and prevention of this hazard by many of my colleagues in several technical departments of the laboratories.

\section{REFERENCES}

Dunn, C. W. (1940). J. Amer. med. Ass., 115, 2263. Scarff, R. W., and Smith, C. P. (1942). Brit. J. Surg., 29, 116, 393. 


\section{CASE NOTES}

Case 1. February 19th, 1940: aet. 18. On production. Exposure 1 month. Complained of pain and swelling in the breasts and tiredness. Both breasts visibly enlarged. In each a soft localized hemispherical tumour, about 1 -inch diameter, taking the shape of the breast April 8th, 1940: no change. Biopsy was performed and the report from the Bland Sutton Institute of Pathology was as follows:- " The breast tubules show a marked degree of epithelial overgrowth with, in places, solid acinar formation. Areas show an indistinct basal

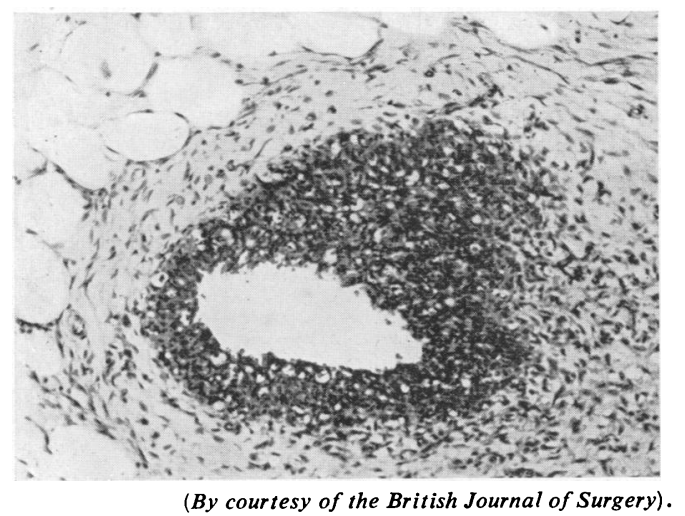

Fig. 1.-Showing Case 1. Man aged 18.

membrane, but nowhere is there any definite invasion of tissue by epithelial cells . . . there is evidence of stimulation of mammary activity ... . severe in (this case). (S.S. 318/1940). September 4th, 1940: right breast still enlarged; swelling around biopsy scar which is tender; both breasts tender. June 28th, 1941: right breast tender swelling, 2-inch diameter, mainly superior to, but partly deep to scar. Left breast, smaller tender swelling. Patient then left. He was the only one in whom signs persisted for so long.

Case 2. February 19th, 1940: aet. 23. On production. Exposure 3 months. Complained of tender swelling of right nipple, tingling in nose, flushes, tiredness and gain of weight. Right breast visibly enlarged; hard localized tender hemispherical swelling, $1 \frac{1}{2}$-inch diameter. Left breast no abnormality. March 1st, 1940: right swelling smaller, 1 inch in diameter. March 21st, 1940: left breast now enlarged; he had noticed this for 14 days; hard tender nodule under and equal in size to areola. Right slightly smaller; tender hard mass underlying areola and extending outwards for $\frac{1}{2}$ inch. July 29th, 1940: no signs.

Case 4. February 26th, 1940: aet. 17. On production during alternate weeks for 3 months. He had no symptoms. There were no visible signs, but in both breasts there was a well defined nummular plaque, 1 inch across, about the thickness of a florin, deep to the areola. March 21st, 1940: smaller. September 4th, 1940: no physical signs.

Case 6. February 27th, 1940: aet. 27. Laboratory work, mainly with alcohol and ether solutions, for 2 months. Had noticed tenderness in breasts after 3 weeks' work. Then started wearing gloves. No symptoms now. Breasts, no visible signs, small hard nodule $\frac{1}{2}$-inch diameter. March 11th, 1940: plaques as Case 4, palpable axillary glands. April 8th, 1940: no change. Biopsy performed and the report from the Bland Sutton Institute of Pathology was as follows:'Section shows gland tubules in a moderately cellular stroma. For the most part the tubules are regular in appearance and lined by a single layer of cubical epithelium, but there are areas of epithelial overgrowth and occasionally solid columns of cells . . . there is evidence of stimulation of mammary activity . . . slight in (this case).' (S.S. 315/1940). April 25th, 1940: no sign except biopsy scar. After a holiday he returned with no symptoms at all. March, 1944: no abnormality except occasional irritation in breasts.

Case 9. February 29th, 1940: aet. 24. Production intermittently for 1 month. No signs or symptoms. He left in April and wrote at the end of June that he had developed a lump in his breast and was going to be operated on. Reports sent to me later by the doctor said that on July 2nd a local excision of the left breast was performed for mastitis, and the section showed a simple fibro-adenoma with no evidence of malignancy; that in September the wound was soundly healed and that there was no sign of inflammation. January, 1941: he came to see me and told me that he had noticed nothing wrong until June, 1940; the left breast then became sore, tender and visibly swollen; he could feel a hard lump in the centre of the swelling about the size and shape of a florin. No symptoms or signs.

Case 13.* January 1st. 1941: aet. 23. Production 3 months, but had not been exposed to any of the oestrogenic stages of manufacture until an accident on December 20th, 1940, when he had been splashed with a resinous, sticky mixture containing stilboestrol which was removed from his skin with great difficulty. Three days later he had pain and tenderness in both breasts. In each breast there is a hard nodule, 1-inch diameter, and the whole breast is swollen and tense; much subcutaneous fat. January 15th, 1941: nodules larger. January 29th, 1941: nodules smaller but breasts still full. February 25th, 1941: left nodule gone; right, small plaque where nodule was. March 24th, 1941: only general fulness of the breasts. May 28th, 1941: breasts now 'back to their normal state'; diffuse mass palpable under subcutaneous fat. August 28th, 1941: no fulness and less fat.

Case 18. March 12th, 1942: aet. 29. Production in new department 6 months with no trouble. After removing respirator he noticed a fair quantity of white powder inside the filter. Subsequent inquiry showed that an alteration had been made in the material used for the filters without any warning of the change having been given by the manufacturers. Since then Mark IV Dust respirators have been used exclusively. Breasts-no signs; lower borders of both pectoralis muscles felt thickened. March 27th, 1942: no physical signs. July 15th, 1942: left hard plaque, 1 inch in diameter. $\mathrm{He}$ had continued work but was advised to stop. Animal tests in May and July were negative; none were carried out in June. July 22nd, 1942: plaque smaller, softer. August 7th, 1942: very small. September 1st, 1942: no signs.

Case 19. July, 1942: aet. 34. After 4 months' work he reported irritation in right breast. There was a hard tender plaque, 1 inch in diameter, in the breast. September, 1942: small thick plaques, $\frac{1}{2}$-inch diameter, in both breasts. March, 1943: no signs in breasts.

Case 20. July 8th, 1943: aet. 25. Production in new department 15 months. Routine periodic examination revealed plaques, $\frac{3}{4}$-inch diameter, both breasts. He had noticed no abnormality. Previous examination in May had revealed no abnormality. He thought the trouble might have been caused by an accident when a flask broke some time before. However, it was soon discovered that during the absence of his chief, heavy pressure of work had led him to perform in the main room part of the process that should have been performed in the cabinet. July 20th, 1943: plaques smaller and softer. August 28th, 1943: little induration around nipples. October 23rd, 1943: no signs.

* Cases 12-20 occurred after the new department was opened. 